\title{
DOCUMENTACIÓN 3D DE LA COVA DELS CAVALLS Y DE SU ENTORNO (TÍRIG, CASTELLÓN)
}

\author{
3D DOCUMENTATION OF THE COVA DELS CAVALLS AND ITS SURROUNDINGS (TÍRIG, CASTELLÓN)
}

\author{
Miriam Cabrelles*, José Luis Lerma
}

Grupo de Investigación en Fotogrametría y Láser Escáner (GIFLE). Departamento de Ingeniería Cartográfica, Geodesia y Fotogrametría, Universitat Politècnica de València, Camino de Vera, s/n, Edificio 7i, 46022 Valencia. micablo@doctor.upv.es; illerma@cgf.upv.es

\begin{abstract}
:
Archaeological cultural heritage is a precious resource that should be transmitted to future generations. The 3D digital representation of monuments and sites has proven to be a reliable method for this aim. This article shows the geomatics workflow undertaken for the complex rock art documentation of the Cova dels Cavalls (Tírig, Castellón). The paintings are part of the Rock art of the Mediterranean Basin of the lberian Peninsula declared a UNESCO's World Heritage Site in 1998. The various stages are reviewed, from the acquisition phase up to the delivery of part of the derived metric products, such as 3D models and photorealistic models.
\end{abstract}

Key words: Geomatics, Rock Art, Photogrammetry, 3D Modelling, Cultural Heritage Documentation, Laser scanning

\section{Resumen:}

El patrimonio cultural arqueológico es un bien preciado que debe transmitirse a las generaciones futuras. La representación digital 3D de monumentos y sitios ha demostrado ser un método fiable para ello. El artículo que se presenta muestra el flujo de trabajo geomático desarrollado en las labores de documentación del conjunto de arte rupestre de la Cova dels Cavalls (Tírig, Castellón). Las pinturas forman parte del Arte rupestre del Arco Mediterráneo de la Península Ibérica declarado Patrimonio de la Humanidad por la UNESCO en 1998. Se revisan las distintas etapas, desde la fase de captura hasta la entrega de parte de los productos métricos derivados, como son los modelos 3D y los modelos fotorrealísticos.

Palabras clave: Geomática, Arte Rupestre, Fotogrametría, Modelización 3D, Documentación Patrimonio Cultural, Láser escáner

\section{Introducción}

Este artículo presenta la metodología de documentación métrica y los resultados obtenidos hasta el momento en el levantamiento de la Cova dels Cavalls, utilizando técnicas fotogramétricas y de escaneado láser terrestre.

La documentación del arte rupestre tiene una doble finalidad: la de servir de herramienta de investigación y conocimiento, y el de requisito de protección patrimonial que permite el seguimiento de la conservación y facilita el registro físico de un fenómeno sujeto a potencial deterioro o pérdida con el paso del tiempo (Martínez and Villaverde 2002). En el campo de la arqueología de arte rupestre prehistórico, generalmente nos encontramos con pinturas y/o grabados.

Existen diferentes alternativas a la hora de abordar levantamientos complejos (Lerma et al. 2010b). La primera opción es la fotogrametría a partir de imágenes como base y el escaneado láser como complemento (Remondino et al. 2009). La segunda es el escaneado láser como base y la fotogrametría a partir de imágenes como complemento en zonas concretas. Y la tercera opción es la integración de ambas soluciones (Lerma et al. 2011). En levantamientos a gran escala se utilizan otras alternativas para capturar información geoespacial como son la utilización de medios aéreos ya sea por medio de aerofotogrametría o LiDAR (Remondino et al. 2016). Recientemente han aparecido sistemas de cartografiado móvil que pueden montarse en una mochila y ser manejados por un único operador mientras camina a un ritmo natural (Fallon et al. 2012; Zlot and Bosse 2014). Soluciones del mismo tipo pero más comerciales, pueden consultarse en GEXCEL (2017), Leica Geosystems (2017) y CSIRO (2015).

En la documentación de la Cova dels Cavalls se optó por utilizar la segunda alternativa, utilizando en primer lugar un escáner láser terrestre para establecer la geometría espacial del conjunto y de su entorno, obteniéndose el modelo $3 \mathrm{D}$ de la Cova como base métrica del trabajo. En segundo lugar se realizó una secuencia de fotografías del abrigo para obtener modelos texturizados a alta resolución de los paneles decorados.

La Figura 1 describe el flujo de trabajo seguido en el levantamiento fotogramétrico a diferentes escalas que nos ocupa. En primer lugar aparece la captura de datos con diferentes sensores (láser escáner y cámara), seguido del procesamiento de los mismos con la

“Corresponding Author: Miriam Cabrelles, micablo@doctor.upv.es 
finalidad de obtener en cada caso modelos 3D, bien a escala general o de detalle.

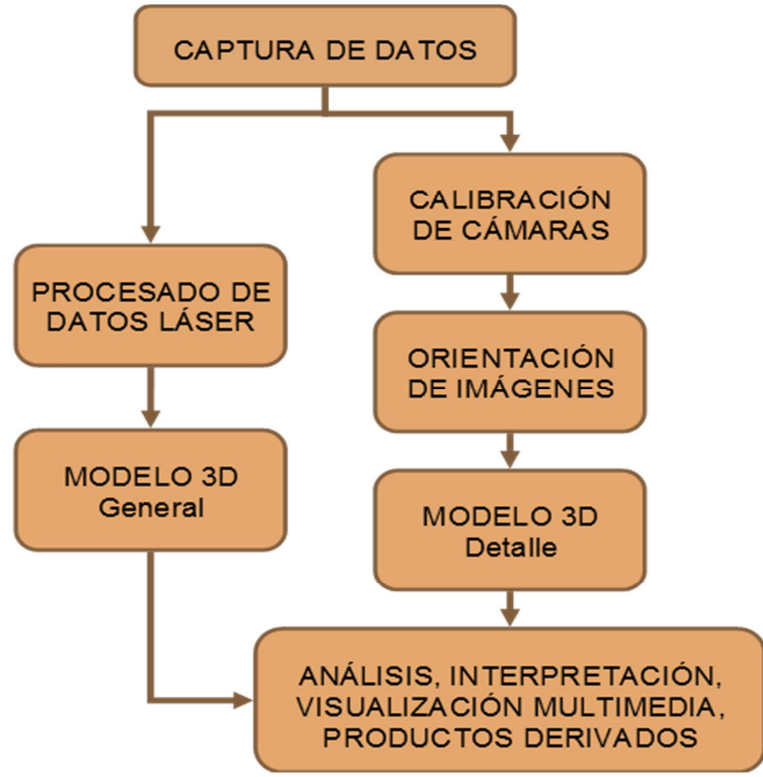

Figura 1: Esquema de un levantamiento fotogramétrico a diferentes escalas.

\section{Caso de estudio}

Las pinturas rupestres de la Cova dels Cavalls, situada en el Barranc de la Valltorta (Tírig, Castellón), fueron descubiertas en febrero de 1917. Poco después, en 1924, el conjunto fue declarado Monumento HistóricoArtístico. La Cova dels Cavalls cuenta con dos abrigos (Fig. 2). El Abric I de escasa concavidad y reducido número de motivos y el Abric II subdividido en dos cavidades de extensión más o menos equivalente en lo que se refiere a su superficie decorada (Martínez and Villaverde 2002). En la actualidad el conjunto conserva motivos de Arte Esquemático y representaciones de Arte Levantino. Entre las escenas destaca la cacería de ciervos, una de las composiciones más emblemáticas del arte rupestre a nivel mundial (Fig. 3).

La Cova dels Cavalls, de orientación noroeste, se abre en una pared vertical a $67 \mathrm{~m}$ sobre el lecho del Barranc de la Valltorta. Se encuentra ubicada en el margen izquierdo del barranco, junto a la Roca de les Tàbegues (Fig. 4).

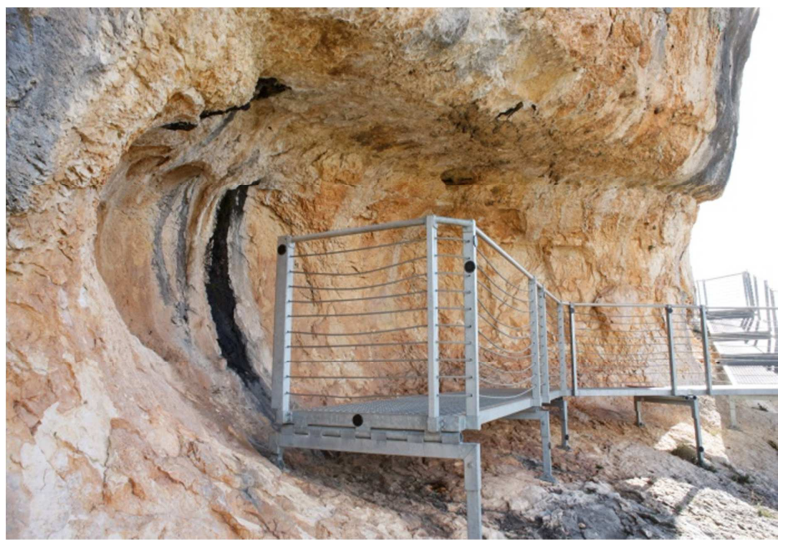

Figura 2: Abric II de La Cova dels Cavalls.

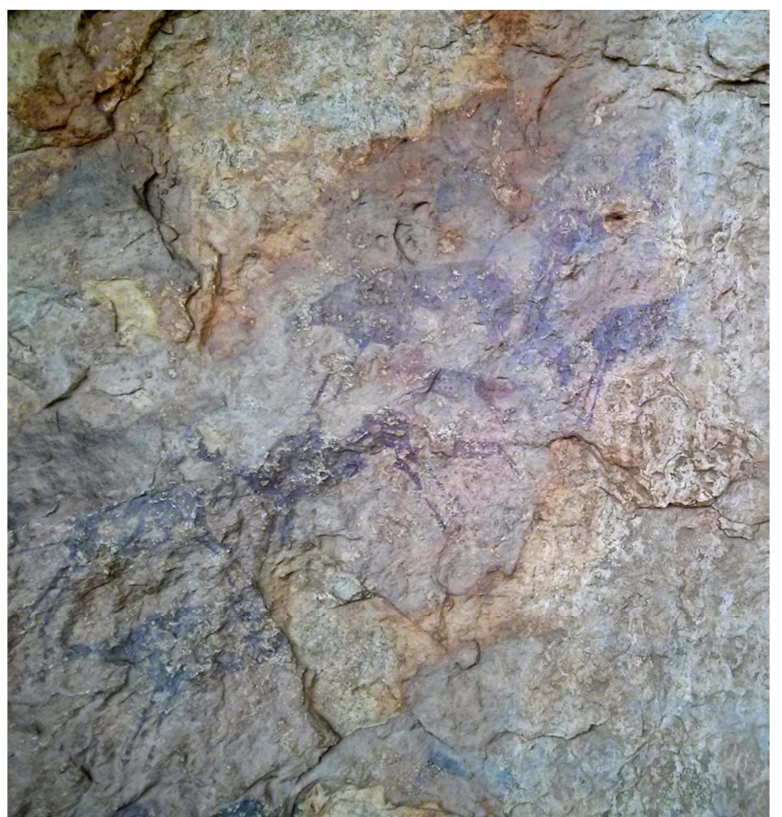

Figura 3: Escena principal de la Cova del Cavalls (detalle). Febrero de 2017

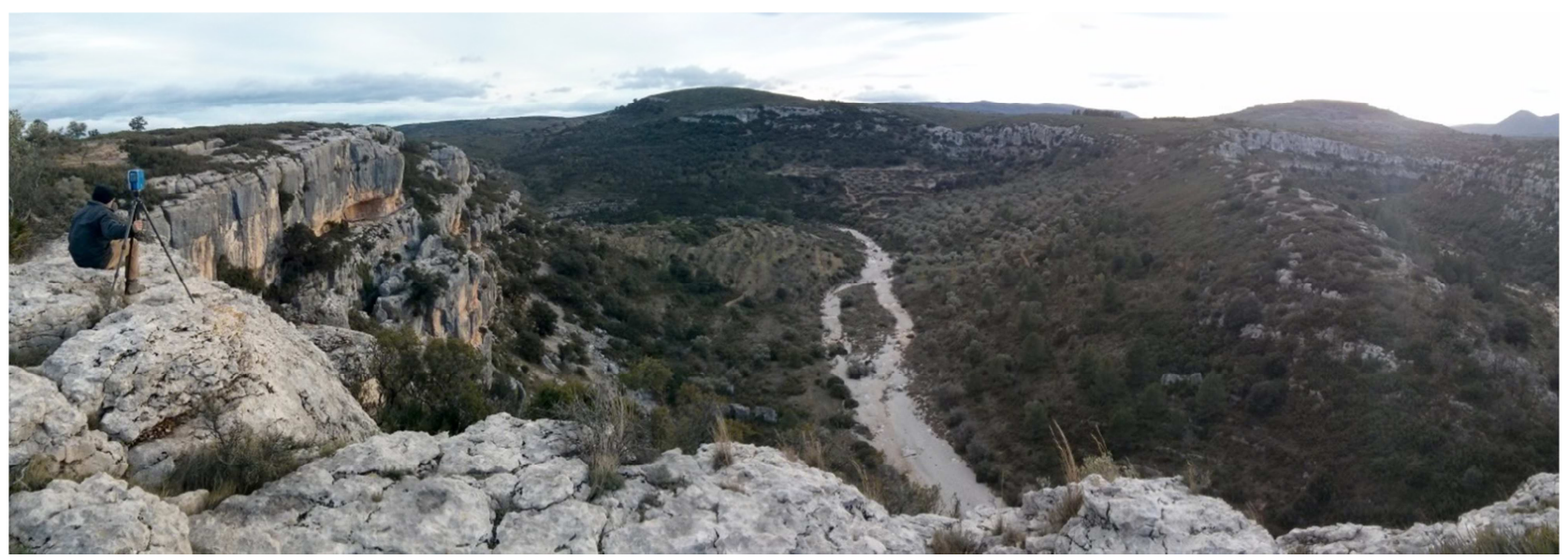

Figura 4: Meandro del Barranc de la Valltorta donde se sitúa la Cova dels Cavalls (febrero de 2017). 


\section{Captura de datos}

Esta parte del trabajo es fundamental en cualquier proceso de documentación, ya que un buen diseño de la toma de datos condiciona la calidad de los resultados obtenidos posteriormente durante la fase de procesamiento (Lerma et al. 2008).

La captura de datos se llevó a cabo en febrero de 2017. En primer lugar se tomaron los datos necesarios para el levantamiento de La Cova dels Cavalls a escala 1/15 y de su entorno a escala más general. La instrumentación utilizada fue el láser escáner terrestre FARO Focus ${ }^{3 D} X$ 330 (Fig. 5). El alcance máximo de este equipo es de 330 metros. Está diseñado para aplicaciones en exteriores gracias a su poco peso, sus reducidas dimensiones y su GPS integrado (FARO Technologies Inc. 2017). En total, se realizaron 14 escaneados: diez escaneados a resolución 1/2 (3 $\mathrm{mm} / 10 \mathrm{~m})$ para el levantamiento de la Cova y cuatro escaneados a resolución máxima $(1,5 \mathrm{~mm} / 10 \mathrm{~m})$ para el levantamiento de parte del Barranc de la Valltorta (Figs. 4 y 6). Los estacionamientos del escáner se eligieron para garantizar la máxima cobertura 3D de la Cova.

En segundo lugar, se tomaron imágenes con la cámara Canon EOS-1Ds Mark III con objetivo Canon de 24 mm y trípode Manfrotto. La cámara tiene formato completo de $35 \mathrm{~mm}$ y cuenta con un sensor CMOS de 21 megapíxels, para más información sobre sus características consultar Canon Europe LTD (2017). Las imágenes se tomaron exclusivamente del Abric II, con la finalidad de obtener un modelo de muy alta resolución que permitiera el estudio de las pinturas en $3 D$ con textura fotográfica.

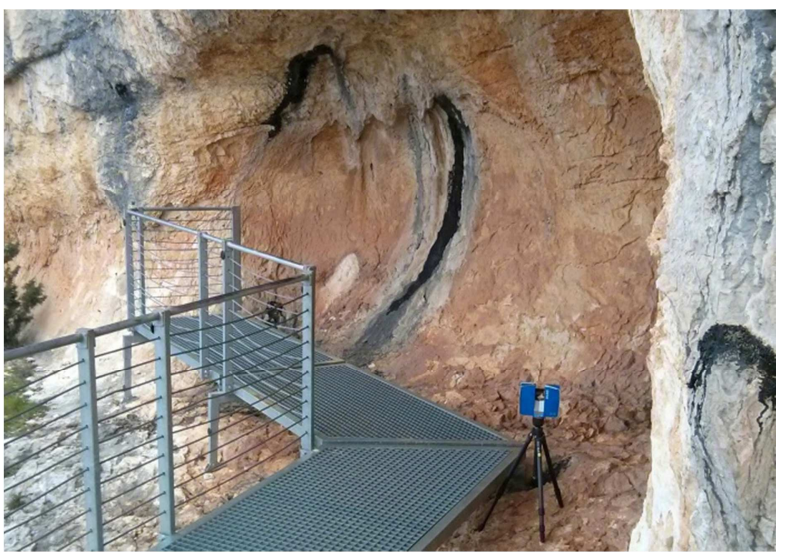

Figura 5: Estacionamiento del láser escáner frente a la Cavidad 2 del Abric II de La Cova dels Cavalls.

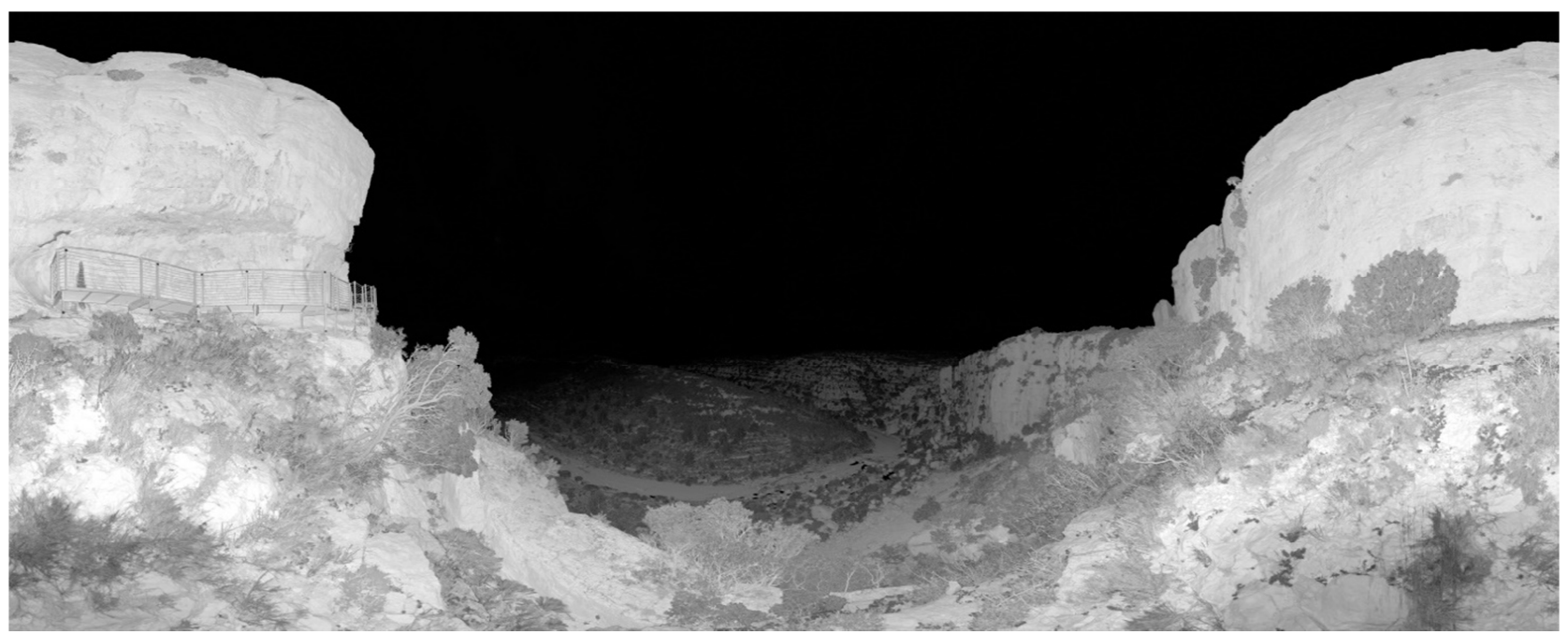

Figura 6: Imagen panorámica de una nube de datos láser correspondiente a la Cova dels Cavalls y su entorno.

\section{Procesamiento de datos láser}

El volumen de datos láser crudos ascendió aproximadamente a 678 millones de puntos espaciales $(\mathrm{X}, \mathrm{Y}, \mathrm{Z})$ junto con sus valores de intensidad (I). La Figura 6 muestra una imagen panorámica de la nube de puntos 3D capturados en un escaneado.

La fase de procesamiento de los datos láser comienza con la transformaron de las nubes de puntos capturadas en los sistemas de referencia instrumentales (locales) a un único sistema de coordenadas objeto $X Y Z$. Esta acción se conoce como registro de las nubes de puntos. Para ello es necesario disponer de al menos cuatro puntos homólogos entre pares de escaneados. La correcta distribución de dichos puntos en el espacio 3D es importantísima a la hora de tener buenos resultados en el ajuste.

Se optó por utilizar el software 3DVEM Register, en lugar del programa FARO Scene, que está desarrollado e implementado por miembros del Grupo de Investigación en Fotogrametría y Láser Escáner (GIFLE) de la Universitat Politècnica de València. 3DVEM Register resuelve el registro, la alineación 0 la orientación relativa (traslación y rotación), de nubes de puntos y/o modelos $3 \mathrm{D}$, a partir de un número suficiente de entidades homólogas identificadas en diversos formatos ASCII. Las entidades homólogas podrán ser centros de dianas y esferas, entre otras, así como puntos naturales o puntos extraídos 3D a partir de modelos digitales o nubes de puntos densas. El emparejamiento de las entidades en el registro es en principio automática, ya que el programa establece las homologías de manera interna, y compensa el registro indirecto mediante mínimos cuadrados 0 con estimadores robustos, en función de la opción que seleccione el usuario. Para tener más información sobre las posibilidades de dicho software véase Fabado et al. (2013), Muñumer and Lerma (2015) y Artese et al. 
(2014). La Figura 7 muestra la ventana principal del programa 3DVEM - Register.

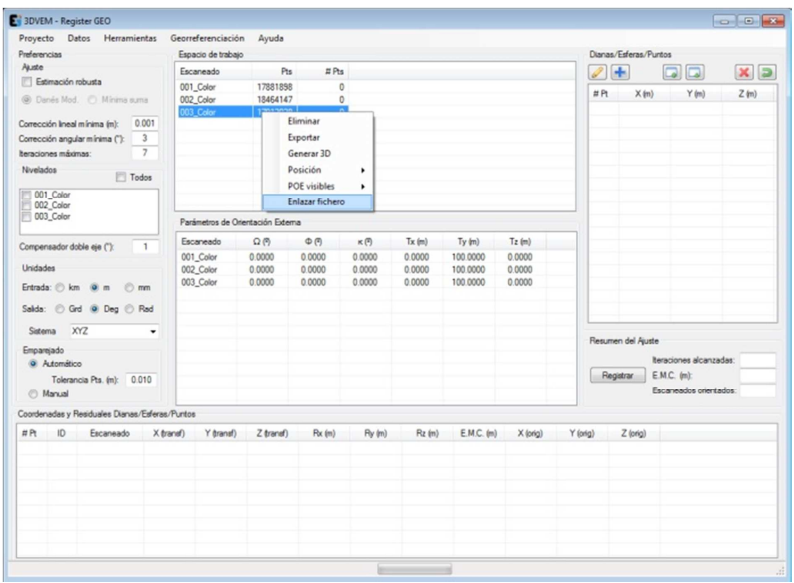

Figura 7: Ventana principal del software 3DVEM Register.

Para poder llevar a cabo el registro de los diferentes escaneados fue necesario determinar a posteriori los puntos homólogos entre los diferentes escaneados. Para ello y debido a la ausencia de esferas o dianas colocadas in situ el día del levantamiento se procedió a medir puntos naturales con el software 3DReshaper versión 5.3 (Fig. 8). Es importante reseñar que gracias a tener el escáner brújula y altímetro, y a llevar activado el GPS, los datos crudos aparecían orientados y con altura aproximada sobre el nivel del mar.

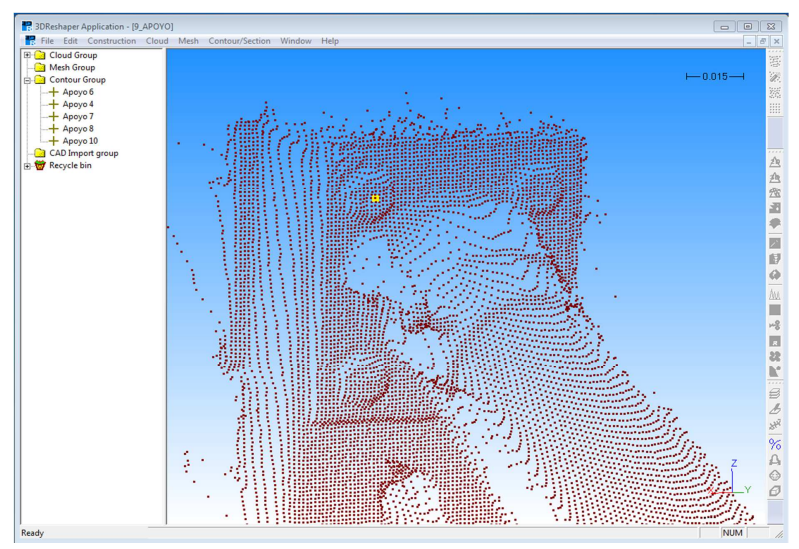

Figura 8: Selección de puntos homólogos con el programa 3DReshaper. En amarillo aparece el punto de la nube de puntos seleccionado.

El siguiente paso consistió en la depuración de los datos. Para ello se filtraron redundancias y se eliminaron elementos ajenos al yacimiento como puede ser la escalera de acceso. Además, se redujo el ruido del escáner con las herramientas de filtrado del software 3DReshaper (TECHNODIGIT 2015).

\section{Obtención del modelo 3D a partir de datos láser}

A partir de las nubes de puntos registradas y filtradas se obtuvo el modelo tridimensional de la Cova del Cavalls tras un proceso de triangulación 3D. La Figura 9 muestra una vista en perspectiva del modelo 3D generado de la Cova dels Cavalls. El software utilizado fue 3DReshaper.

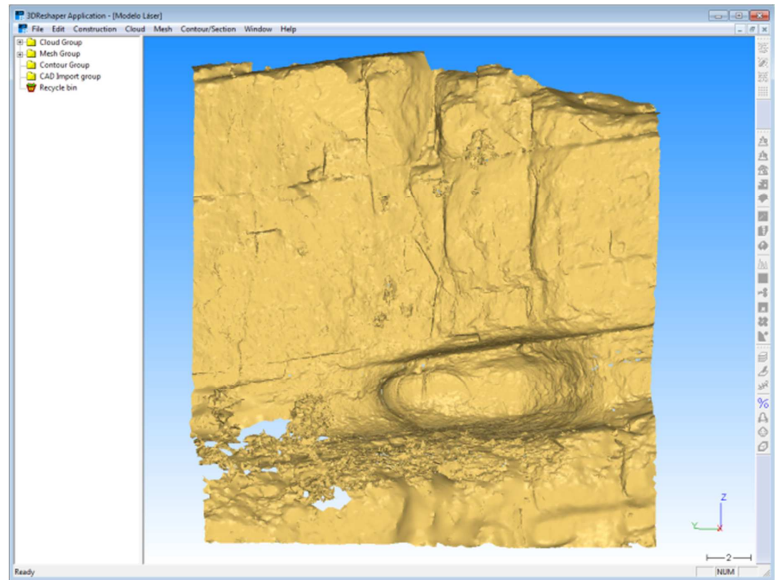

Figura 9: Vista en perspectiva del modelo láser 3D.

\section{Calibración de cámaras}

La calibración de la cámara ha sido siempre un componente esencial de la medición fotogramétrica. La auto-calibración durante el proyecto es una operación rutinaria pero esencial aplicada en trabajos de precisión de objeto cercano como el que se describe. En cualquier caso, los seis parámetros de orientación exterior que definen la posición espacial y la orientación de la cámara y los parámetros de orientación interior se determinan simultáneamente por medio de un ajuste por mínimos cuadrados de las ecuaciones de colinealidad con parámetros adicionales (Lerma et al. 2010a). Según Remondino and Fraser (2006) la calidad de la autocalibración depende de la geometría global de la red, y especialmente de la configuración de las tomas. Deben tomarse imágenes altamente convergentes, con tomas giradas ortogonalmente y un gran número de puntos objeto bien distribuidos.

Para determinar los parámetros de orientación interna de la cámara se eligieron un total de 35 imágenes convergentes correspondientes a la Cavidad 1 del Abric Il de la Cova dels Cavalls (Fig. 10). El software utilizado fue Agisoft PhotoScan Professional (versión 1.3.1). Puede consultarse más información sobre dicho software en Agisoft (2017).

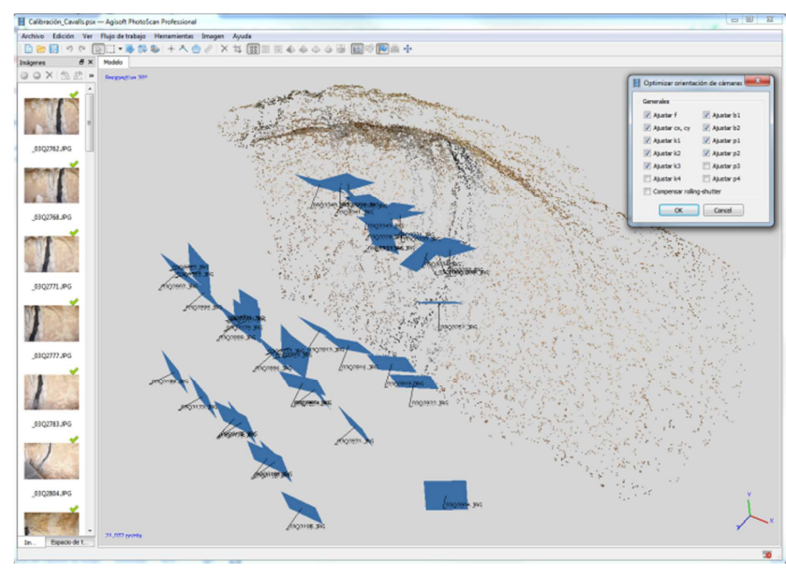

Figura 10: Vista del proyecto de calibración. Visualización de los puntos $\mathrm{XYZ}$ utilizados en el ajuste y de la posición espacial de cada imagen. 


\section{Orientación de las imágenes}

Una vez calibrada la cámara se procedió a orientar en el espacio las 200 imágenes tomadas del Abric II. El software utilizado en esta fase fue también Agisoft PhotoScan Professional. Las imágenes se orientaron en bloque para obtener sus parámetros de orientación externa (Fig. 11). Posteriormente se realizó una transformación de semejanza 3D para determinar la orientación absoluta de las imágenes del bloque fotogramétrico respecto a los datos láser. Para ello se identificaron en las imágenes puntos naturales pertenecientes a la nube de datos del láser.

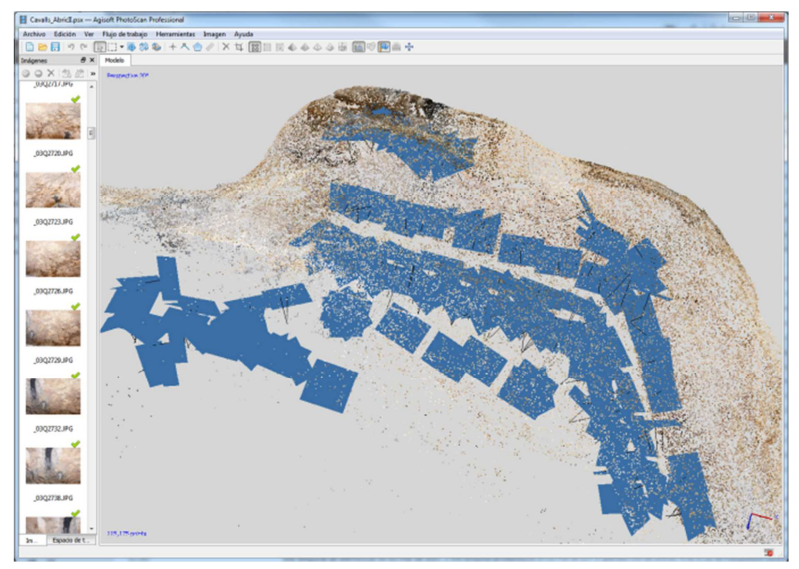

Figura 11: Vista del proyecto de orientación de las imágenes. Visualización de los puntos XYZ utilizados en el ajuste y de la posición espacial de cada cámara.

\section{Obtención del modelo 3D a partir de las imágenes}

Este proceso es similar al descrito en el epígrafe 5. A partir de la nube de puntos densa obtenida por correlación de imágenes se obtuvo el modelo tridimensional tras un proceso de triangulación 3D. La Figura 12 muestra una vista en perspectiva de la nube de puntos densa generada por el software Agisoft PhotoScan Professional. El software utilizado para generar y depurar el modelo 3D fue 3DReshaper, en lugar de la solución automática que ofrece el programa utilizado con anterioridad. De esta manera se consigue mejorar sustancialmente la calidad del modelo geométrico 3D resultante.

\section{Productos derivados}

La documentación arqueológica requiere de soluciones efectivas que permitan archivar, visualizar, gestionar, analizar y monitorizar los distintos yacimientos y sitios existentes.

Aparte de la documentación topográfica habitual en base a planimetrías y altimetrías, pueden derivarse productos métricos como son los modelos 3D, los modelos fotorrealísticos (Fig.13) y los ortofotomosaicos con niveles de detalle y precisiones variables de acuerdo a las distintas aplicaciones (visores web, realidad virtual, etc.).

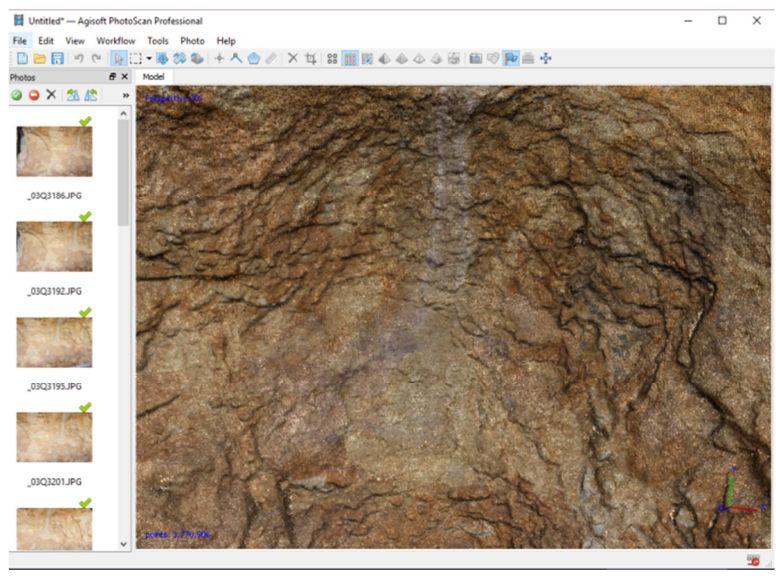

Figura 12: Vista en perspectiva de la nube de puntos densa (detalle).

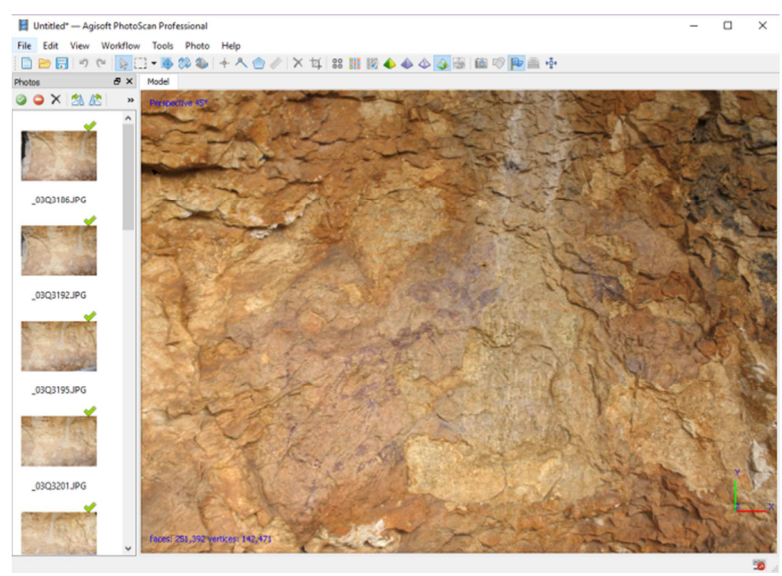

Figura 13: Vista en perspectiva del modelo texturizado (detalle).

\section{Conclusiones}

Los objetivos iniciales del proyecto son la documentación minuciosa del conjunto arqueológico de la Cova dels Cavalls (Tírig, Castellón), y de su entorno, implementando una metodología de documentación métrica con base fotogramétrica. Este artículo presenta de manera resumida parte de los trabajos de documentación realizados hasta el momento. Los resultados satisfactorios alcanzados se deben a la integración eficiente de las soluciones fotogramétricas a partir de imágenes digitales y del escaneado láser efectuado.

En un futuro se pretende documentar métricamente y validar el conjunto de la Cova con diferentes niveles de detalle y de precisión, integrando soluciones efectivas, por desgracia no siempre automáticas, en todas las etapas del proceso productivo.

\section{Agradecimientos}

Los resultados presentados se enmarcan dentro del proyecto de investigación HAR2014-59873-R del Ministerio de Economía y Competitividad. Los autores agradecen a Diego Mosquera de FARO Spain su contribución al facilitar el escáner. 


\section{References}

AGISOFT 2017. Agisoft: Features Professional Edition. Available: http://www.agisoft.com/features/professional-edition/ $[6 / 8,2017]$.

ARTESE, S., ALTOMARE, C., LERMA, J.L., and ZINNO, R., 2014. Terrestrial laser scanning registration analysis and its effects on a masterpiece dome. In 3D/4D Documentation in Cultural Heritage, International Conference On Cultural Heritage EuroMed: pp. 89-99.

CANON EUROPE LTD 2002-2017. EOS-1Ds Mark III: the professional workhorse. Available: http://cpn.canoneurope.com/content/product/cameras/eos1dsmark3.do [6/8, 2017].

CSIRO, 2015-2017. Commonwealth Scientific and Industrial Research Organisation. Zebedee: handheld laser scanner. Available: https://www.data61.csiro.au/en/Our-expertise/Expertise-Cyber-physical-systems/Zebedee [5/21, 2017].

FABADO, S., SEGUÍ, A.E., CABRELLES, M., NAVARRO, S., GARCÍA-DE-SAN-MIGUEL, D. and LERMA, J.L., 2013. 3DVEM software modules for efficient management of point clouds and photorealistic 3D models. The International Archives of the Photogrammetry, Remote Sensing and Spatial Information Sciences, Volume XL-5/W2, 2013 XXIV International CIPA Symposium, 2 - 6 September 2013, Strasbourg, France. ISSN 1682-1777. pp. 255 - 260.

FALLON, M.F., JOHANNSSON, H., BROOKSHIRE, J., TELLER, S. and LEONARD, J.J., 2012. Sensor fusion for flexible human-portable building-scale mapping. IEEE/RSJ International Conference on Intelligent Robots and Systems, Vilamoura, pp. 4405-4412. doi: 10.1109/IROS.2012.6385882.

FARO TECHNOLOGIES INC., 2017. FARO Focus Laser Scanner S, M \& X Series - Perfect instruments for 3D Documentation and Surveying. Available: http://www.faro.com/es-es/productos/topografia-3d/laser-scanner-farofocus-3d/caracteristicas [6/8, 2017].

GEXCEL, 2017. HERON wearable laser scanner. Available: http://www.gexcel.it/en/heron-overview [5/21, 2017].

LEICA GEOSYSTEMS AG - PART OF HEXAGON, 2017. Leica Pegasus: Backpack Wearable Mobile Mapping Solution. Available: http://leica-geosystems.com/products/mobile-sensor-platforms/capture-platforms/leica-pegasus-backpack [5/21, 2017].

LERMA GARCÍA, J.L., SANTANA QUINTERO, M., HEINE, E., and GENECHTEN, B. VAN., 2008. Theory and practice on terrestrial laser scanning. Training material bases on practical applications. (J.L. Lerma García, M. Santana Quintero, E. Heine, \& B. Van Genechten, Eds.). Valencia: Editorial Universitat Politècnica de València.

LERMA, J.L., NAVARRO, S., CABRELLES, M. and SEGUI, A.E, 2010a. Camera Calibration with Baseline Distance Constraints. The Photogrammetric Record 25(130), pp. 140-158. DOI: 10.1111/j.1477-9730.2010.00579.x.

LERMA, J.L., NAVARRO, S., CABRELLES, M. and VILLAVERDE, V., 2010b. Terrestrial laser scanning and close range photogrammetry for 3D archaeological documentation: the upper Palaeolithic cave of Parpallò as a case of study. Journal of Archaeological Science, 37(3), pp. 499-507.

LERMA, J.L., NAVARRO, S., CABRELLES, M., SEGUÍ, A.E., HADDAD, N. and AKASHEH, T., 2011. Integration of laser scanning and imagery for photorealistic 3D architectural documentation. In: Laser Scanning, Theory and Applications (Chau-Chang Wang, Ed.). Intech, pp. 414-430.

MARTíNEZ VALLE, R. and VILLAVERDE BONILLA, V., 2002: La Cova dels Cavalls en el barranc de la Valltorta. Monografías del Instituto de Arte Rupestre. Museu de la Valltorta. Tirig. Publisher: Generalitat Valenciana, Editor: R. Martínez Valle \& Valentín Villaverde, ISBN: 84-482-3333-6. 210 pages.

MUÑUMER, E. and LERMA, J.L., 2015. Fusion of 3D Data from Different Image-based and Range-based Sources for Efficient Heritage Recording. International Congress on Digital Heritage - Theme 1 - Digitization And Acquisition, http://dx.doi.org/10.1109/DigitalHeritage.2015.7413840.

REMONDINO, F. and FRASER, C., 2006. Digital camera calibration methods: considerations and comparisons. In: H.-G. Maas and D. Schneider (H.-G. Maas and D. Schneider, ISPRS Commission V Symposium 'Image Engineering and Vision Metrology', Dresden, Germany, 25-27 September, pp. 266-272.

REMONDINO, F., GIRARDI, S., RIZZI, A. and GONZO, L., 2009. 3D modeling of complex and detailed cultural heritage using multi-resolution data. ACM Journal on Computing and Cultural Heritage, 2(1), 1-20.

REMONDINO, F., GAIANI, M., APOLLONIO, F., BALLABENI, A., BALLABENI, M. and MORABITO, D., 2016. 3D documentation of 40 kilometers of historical porticoes - The challenge. The International Archives of the Photogrammetry, Remote Sensing and Spatial Information Sciences, Volume XLI-B5, 2016 XXIII ISPRS Congress, 12-19 July 2016, Prague, Czech Republic.

TECHNODIGIT PART OF HEXAGON, 2015. 3DReshaper, One Software, Infinite Applications. Available: http://www.3dreshaper.com/en/ [6/8, 2017].

ZLOT, R. and BOSSE, M., 2014. Three-dimensional mobile mapping of caves. Journal of Cave and Karst Studies, v. 76 , no. 3, pp. 191-206. DOI: 10.4311/2012EX0287. 